\title{
O DECÉNIO FINAL NA BIOGRAFIA DE CARVALHO CALERO (1980-1990)
}

THE FINAL DECADE IN THE BIOGRAPHY OF CARVALHO CALERO (1980-1990)

\section{José-Martinho Montero Santalha Universidade de Vigo}

\begin{abstract}
Resumo: O decénio final da biografia de Ricardo Carvalho Calero estende-se desde o momento da sua jubilação como professor universitário em 1980 até o seu falecimento em 1990. Neste artigo apresenta-se uma perspectiva da sua actividade cultural (nomeadamente das suas publicações) nesse período.
\end{abstract}

\begin{abstract}
The final decade in the biography of Ricardo Carvalho Calero begins with his retirement as a University professor in 1980 and ends with his death in 1990. This article presents an overview of his cultural activity (especially his publications) during this period.
\end{abstract}

Palabras chave: Ricardo Carvalho Calero, literatura galega do século XX, língua galego-portuguesa, reintegracionismo linguístico.

Key words: Ricardo Carvalho (Carballo) Calero, 20th-century Galician literature, Galician-Portuguese, linguistic reintegrationism.

Agradeço cordialmente, antes de nada, à Real Academia Galega ${ }^{1}$ o convite para participar neste simpósio sobre Carvalho Calero. Sinto-me muito honrado de falar aqui, nesta instituição venerável, que tem, como todos bem sabemos, muito de símbolo da nossa identidade galega. Por terem sido os contactos directos neste convite não quero deixar de citar os nomes queridos e admirados do presidente

1 O presente texto corresponde à minha intervenção na primeira sessão do Simposio Ricardo Carballo / Carvalho Calero 2020, organizado pela Real Academia Galega como parte da homenagem ligada à celebração do Dia das Letras Galegas do ano 2020. Essa sessão, sob o tema comum "O tempo de Carballo Calero", celebrou-se na sede da RAG na Corunha no dia 8 de outubro, com participação de Justo G. Beramendi e Carmen Blanco e moderação do académico Ramón Villares. 
Víctor Freixanes e do secretário Henrique Monteagudo, e especialmente o do académico Ramón Villares, com quem me une uma amizade que tem as suas raízes nos afastados anos da nossa infância ou adolescência no Seminário de Mondonhedo e a quem agora quero agradecer a carinhosa apresentação.

Corresponde-me falar do decénio final da vida de Carvalho Calero, entre os anos 1980 e 1990; isto é, entre o momento da sua jubilação e o seu falecimento. E não deixo de sentir um certo reparo íntimo por ter que ocupar-me dessa parte da sua biografia, que encerra feridas que nos afectaram a muitos e em primeiro lugar a ele. Talvez os acontecimentos que configuram a sua biografia mais visível nestes anos não foram determinantes, salvo naturalmente aqueles que assinalam o começo e o fim deste período. Por isso pode ser útil deter-nos em feitos menos visíveis socialmente mas de grande influxo na sua vida mais pessoal, embora às vezes possuam carácter quase anecdótico.

\section{PREÂMBULO DE ÍNDOLE PESSOAL}

Quisera começar indicando que, por circunstâncias casuais em boa medida mas também pela minha veneração pela sua obra e pela sua pessoa, estive bastante perto de Carvalho Calero durante esse decénio final da sua vida.

Fui seu colaborador em diversos trabalhos e iniciativas, especialmente nas atividades da primitiva AS-PG (Associação Sócio-Pedagógica Galega) com as várias "Jornadas do Ensino", e sobretudo da AGAL (Associação Galega da Língua) com a sua fundação, os actos de apresentação pública, os seus primeiros congressos e com o lançamento da revista Agália.

Preparei-lhe, por sua encomenda, a edição do seu livro Da fala e da escrita, que transcrevi em normativa reintegrada e mecanografei integramente durante os meses de setembro e outubro de 1982 e que se publicaria no ano seguinte (1983).

Repetidamente gozei da sua hospitalidade e comi na sua casa da Carreira do Conde (e até dormi uma noite em que ambos regressávamos tarde a Santiago em viagem aérea...).

Houve ademais uma circunstância casual que teve grande importância na nossa relação desses anos finais da sua vida. Resulta que, participando ambos num congresso em Barcelona, colocaram-nos juntos no mesmo quarto do hotel, de maneira que convivemos proximamente durante uma semana inteira. Para mim, que já tinha boa amizade e confiança com ele, foi aquela uma experiência cativante: fiquei realmente fascinado pela sua personalidade, vista desde tão perto. Na memória e no coração levo gravadas as lembranças de aqueles dias de tão próxima convivência e de tantas conversas com ele: da sua atitude de adaptabilidade às diversas circunstâncias, de cooperação e até de cumplicidade com 
iniciativas de gente mais nova, do seu espírito de singeleza e de modéstia (bem diferente da imagem algo distante que à primeira vista produzia)...

\section{PERSPECTIVA DE CONJUNTO PRÉVIA: 3 ASPECTOS}

Tratando de apresentar resumidamente a sua biografia no decénio 1980-1990, podemos distinguir 3 aspectos:

- A sua produção escrita (de criação literária, linguística e de crítica literária).

- O seu activismo cultural: conferências, congressos, encontros vários.

- A sua vida mais pessoal.

Nesta década final de sua vida, Carvalho Calero, já jubilado da docência oficial e libertado portanto de compromissos académicos, não deixou de trabalhar intensamente pela cultura galega.

Desenvolveu, em primeiro lugar, uma grande actividade no campo da criação literária, não só revendo e reeditando toda a sua produção anterior, mas também compondo algumas das suas melhores obras, tanto de narrativa (Scórpio, 1987) como de poesia (Cantigas de amigo e outros poemas, 1986; Reticências..., 1990) e de teatro (Os xefes, 1980, 1982).

Em segundo lugar, dedicou especial atenção aos problemas linguísticos, alarmado perante as novas circunstâncias sócio-culturais que ameaçavam o futuro da língua da Galiza. Publicaram-se então, entre outros, os seus livros Problemas da língua galega (1981), Da fala e da escrita (1983) e Do galego e da Galiza (1990), nos quais ficaram formuladas as suas propostas a respeito da política linguística, que constituem o melhor fundamento teórico do movimento reintegracionista.

Não abandonou tampouco o seu campo preferido da crítica literária galega, com novos trabalhos, em geral de menos volume mas com a mestria de sempre, alguns recolhidos nos seus livros Escritos sobre Castelao (1989) e Estudos e ensaios sobre literatura galega (1989).

E, finalmente, não cessou no seu activismo cultural, não só por meio dos habituais artigos na imprensa, mas também proferindo conferências por qualquer lugar da Galiza, participando em congressos, viajando não só a Barcelona ou a Madrid mas também a Alemanha ou à Argentina...

\section{A SUA PRODUÇÃO ESCRITA: UMA OBRA SILENCIADA}

O primeiro que devemos constatar ao tratar da sua produção escrita neste decénio final é o ocultamento que sofreu. Citarei só duas amostras desse ocultamento.

Pouco depois de falecer Carvalho, o professor Filgueira Valverde (1990) publicou na imprensa um artigo necrológico (mais tarde recolhido num dos seus "adrais"). 
Ora, mesmo como visão divulgativa de conjunto, esta nota necrológica de Filgueira, companheiro de Carvalho desde os tempos juvenis no Seminário de Estudos Galegos e no Partido Galeguista, resulta incompleta em quanto à informação sobre o personagem e sobre a sua produção escrita: significativamente, não se recolhe nenhum dos mais de uma dúzia de livros do derradeiro decénio, em qualquer dos campos (poesia, narrativa, teatro, crítica literária, estudos linguísticos...).

Ainda que parece natural supormos que Filgueira não desconheceria a existência de pelo menos alguns desses livros (que provavelmente seriam adquiridos pela biblioteca do Museu de Pontevedra), resisto-me a crer que neste silenciamento houvesse uma intenção malévola de ocultar aos leitores toda essa produção. Penso que será, antes, índicio de uma atitude algo diferente: simplesmente não considerava valiosas essas obras (que talvez não teria lido), e por isso mesmo provavelmente nem sequer as conhecia em profunidade, de maneira que não só era natural prescindir delas num artigo breve, mas na perspectiva de Filgueira (e de outros com ele) até resultava favorável para o prestígio de Carvalho que na sua lembrança necrológica se ocultassem essas inoportunas "vergonhas"...

A segunda amostra do silenciamento da produção de Carvalho no período final da sua vida está viva hoje mesmo. Se consultarmos o sítio em Internet da Editorial Galaxia acharemos, na secção dos autores, a seguinte ficha:

\section{Ricardo Carballo Calero}

Catedrático de Lingüística e Literatura Galega e escritor. Licenciado en Dereito e Filosofía e Letras pola Universidade de Santiago de Compostela (USC) e doutor en Letras pola Universidade Central de Madrid. Foi o secretario do Seminario de Estudos Galegos e partillou os principios políticos do Partido Galeguista (1931). Foi membro da Real Academia Galega. A partir de 1970 foi o principal teorizador e defensor das teorías do reintegracionismo lingüístico co portugués como vía para a normalización do galego. Do seu traballo académico destacan a Historia da Literatura Galega Contemporánea (1975) e mais Estudos rosalianos (1979). Como poeta, iniciouse en castelán con Trinitarias (1928) e La Soledad Confusa (1931), para continuar en galego con Vieiros (1931) e O silencio ajoellado (1934) ata a súa madurez en Anxo de Terra (1950). Como prosista abriu a xeira da novela galega da posguerra con A xente da Barreira (1950, Premio Bibliófilos Gallegos). Tamén cultivou o xénero dramático de xeito continuado desde 1936, con obras como A sombra de Orfeu, 1948. Dedicóuselle o Día DAS LETRAS GALEGAS 2020.

Naturalmente, trata-se de uma ficha resumida, que não pretenderia apresentar uma perspectiva completa da produção escrita de Carvalho, ainda que a selecção 
pode ser discutível, mesmo para os anos 50-80, quando Galaxia era a sua editora normal. De qualquer modo, devemos constatar que resulta surpreendente mais uma vez o absoluto silenciamento da produção do decénio final.

Em certa medida, algo desse silenciamento deve-se ao próprio Carvalho: especialmente, no que diz respeito à sua produção literária.

Em primeiro lugar, porque o impressionante volume da sua magna Historia da literatura galega contemporánea resultou uma obra tão dominante que deixou na sombra o resto da sua produção. E em segundo lugar, porque essa foi a fonte principal donde todos bebemos informação sobre a nossa literatura, o qual teve como consequência que, dado que ele não se quis incluir nela, a atenção que se veio dando à sua obra literária foi escassa e pobre, e habitualmente reduz-se a umas referências sumárias.

Para esse ocultamento contribuiu ainda mais o feito de que a versão última de toda a sua obra literária publicou-se nesse decénio final da vida, quando já era um escritor "maldito", e ademais com uma revisão linguística na direcção contrária à propugnada pelo "galeguismo oficial".

O caso é que, efectivamente, a obra e a figura de Carvalho foi silenciada em medida que não se justifica unicamente pelo passo do tempo. E no que vai deste ano pude comprovar repetidamente como alguma gente que agora chegou a conhecer algo da vida e da obra de Carvalho, surpreendidos e deslumbrados perante esse descobrimento, manifestavam um certo sentimento de indignação e rebeldia perguntando "Como foi possível que nos ocultassem isto durante todos estes anos?".

\section{REEDIÇÃO DA SUA OBRA LITERÁRIA}

Neste decénio final da vida de Carvalho, a sua actividade criadora não só não se deteve, mas, aproveitando o tempo agora mais livre, intensificou-se. Nestes anos submeteu a revisão linguística e reeditou a sua obra literária completa:

- poesia: Pretérito imperfeito (1927-1961) (1980), Futuro condicional (19611980) (1982);

- narrativa: A gente da Barreira e outras histórias (1982) e Narrativa completa (1984);

- teatro: Teatro completo (1982);

- alguns escritos juvenis sobre temas diversos (La fuerza pública en la Universidad de Santiago y otros escritos escolares (1930-1933) (1987).

Sobre a revisão linguística realizada informava, por exemplo, na "Nota liminar" da edição do seu Teatro completo, datada em setembro de 1981: 
As especiais características do desenvolvimento do galego literário aconsellaron unha revisión da linguaxe dos textos, na que non pretendin, emporiso, forzar unha unificación léxica nen unha morfologia rígida. Mesmo mantiven alguns dialectalismos e vulgarismos na boca de certas personages, dacordo coa sua condición social (Carballo 1982, p. 8).

Um pormenorizado estudo do professor José Luís Rodríguez (2020) sobre as mudanças linguísticas introduzidas na reedição, em 1982, do seu romance A gente da Barreira faz-nos ver a extensão e a profundidade da revisão linguística a que submeteu a sua obra literária precedente. Não há praticamente uma linha do texto onde não realizasse alguma modificação.

No labor de revisão linguística rege-se por critérios inspirados na sua proposta de reintegração galego-portuguesa. Não só evita as formas disparatadas que apareciam nos escritos de pré-guerra, mas também outros vocábulos de conformação ultradiferencialista ou artificiosa; também formas arcaizantes de escasso apoio na fala mais geral, ou castelhanizantes, ou excessivamente localistas, como arestora, asemade, endebén, nembargantes, secomasí... Em geral presta mais atenção a uma norma comum galego-portuguesa; assim, por exemplo, em vez de antre, atopar, castelán, Galicia, Rexurdimento prefere agora usar entre, topar, castelhano, Galiza, Ressurgimento...

\section{LABOR DE CRIAÇÃO E DE CRÍTICA LITERÁRIA}

Ao mesmo tempo, avivou o labor de criação nos diversos campos: no do teatro com a peça Os xefes $(1980,1982)$, no da narrativa com o romance Scórpio (1987), e especialmente no campo da poesia com dois novos livros: Cantigas de amigo e outros poemas (1980-1985) (1986) e Reticências... (1986-1989) (1990, aparecido já postumamente). Provavelmente estas quatro obras assinalam o ponto mais alto, em qualidade, da sua produção como criador literário.

Prosseguiu também o trabalho no campo da crítica literária, uma tarefa sempre grata para ele, graças não só à extensão dos seus conhecimentos histórico-literários tanto clássicos como modernos, mas também à sua faculdade de juízo sereno e perspicaz. Versam especialmente sobre temas literários as obras Libros e autores galegos (II): século XX (1982), Letras galegas (1984), Estudos e ensaios sobre literatura galega (1989) e Escritos sobre Castelao (1989).

Houve ademais neste tempo a reedição da Historia da literatura galega contemporánea (1808-1936) (1981, 3ª edição), com escassas modificações sobre a edição precedente.

Também achamos novos contributos no campo da edição de textos literários (ademais das reedições de trabalhos anteriores, como as obras poéticas de Rosalia): 
o volume Prosa galega III: Da época trovadoresca ao neoclasicismo (1980, em colaboração com Carme García Rodríguez e Lídia Fontoira Suris), as Cantigas de amor, de escarnio e de louvor (1983) do rei Afonso X o Sábio (em colaboração com Carme García Rodríguez) e a Antología literaria bilingüe de Castelao (1983).

\section{TEMÁTICA LINGUÍSTICA}

Neste decénio dedicou grande atenção a todos os problemas relacionados com a vida da língua: com a sua história, com a sua situação presente, com o seu futuro. E publicou novos livros, compilando trabalhos novos e velhos. Tratam mormente temas linguísticos os livros Problemas da língua galega (1981), Da fala e da escrita (1983) e Do galego e da Galiza (1990).

\section{ARTigos JoRnalísticos}

Seguiu colaborando nos jornais, especialmente em La Voz de Galicia, da Corunha. Contando só os artigos aparecidos neste jornal corunhês somam uns 150, muitos deles recolhidos depois no livro Umha voz na Galiza (1992). Apesar de serem artigos de divulgação por causa dos meios em que se publicavam, não faltam neles novas informações, sempre guarnecidas com a mestria do seu juízo.

\section{Os LIVROS PUBLICADOS}

Os livros publicados neste período (prescindindo de alguns escritos de menor importância) foram os seguintes, em ordem cronológica:

Pretérito imperfeito (1927-1961). Sada: Ediciós do Castro, 1980, 236 pp.

Auto-escolha, em edição linguisticamente revista, dos 5 livros poéticos publicados até o ano 1961, apresentada por um "Limiar" (pp. 9-12), datado "Santiago, 27 maio 1980"; a saber, dos livros seguintes: Vieiros (1931), O silenzo axionllado (1931-1934) (1934), Anxo de terra (1950), Poemas pendurados de un cabelo (1952), Salterio de Fingoy (1961). Em total 124 poemas.

Prosa galega III: Da época trovadoresca ao neoclasicismo. Vigo: Galaxia, 1980, $286 \mathrm{pp}$.

Terceiro e último volume da antologia histórica de prosa galega. Como autoria aparece nos três volumes "Cátedra de Lingüística e Literatura Galega", o que o próprio Carvalho explica no "Prólogo" deste derradeiro volume como "a equipa da mesma constituída polo seu titular e as profesoras ajudantes señoras Carme García Rodríguez e Lídia Fontoira Suris" (p. 7). 
Problemas da língua galega. Noroeste 2. Lisboa: Sá da Costa Editora, 1981, 148 pp.

Introduzidos por um "Prefácio" (pp. 1-2), inclui este livro 15 trabalhos. No "Prefácio" o autor adverte: "À excepçom do que vai em cabeça, todos os trabalhos forom publicados com anterioridade, umha ou mais vezes, em revistas, jornais ou colectáneas. Agora vam revisados, e - até onde coubo sem destruir a sua estrutura fundamental - actualizados" (p. 1).

Historia da literatura galega contemporánea (1808-1936). 3. ed. Vigo: Galaxia, 1981, 894 pp.

Nova edição da obra publicada em 1963 e 1975. O "Prólogo à terceira edición" está datado "Santiago, 27 novembro 1979", e adverte: "Nesta edición de agora, tense conservado a estrutura da segunda, e somente aquí e alí anotóuse algún dado novo: unha data de falecimento dun escritor vivo en 1973, un importante libro publicado posteriormente por outro. Fora disto, só correximos algunha noticia menos exacta, as grallas de imprensa e algún vocábulo que ten preferido outro aspecto na rápida evolución do galego escrito".

Futuro condicional (1961-1980). Sada: Ediciós do Castro, 1982, 220 pp.

Trata-se de um novo poemário: auto-escolha de poemas dispersos ou inéditos do período indicado, apresentada por um "Limiar" (p. 9) datado "Santiago, 3 outubro 1981". Em total 125 poemas.

Teatro completo. Sada: Ediciós do Castro, 1982, 247 pp.

Segunda compilação de obras teatrais, apresentada por uma "Nota liminar" (pp. 7-8), datada "Santiago de Compostela, 3 de setembro de 1981". Inclui, nesta ordem (que é a cronológica da composição das obras), as seguintes 8 peças: $O$ fillo (1935), Isabel (1945), A sombra de Orfeu (1948), Farsa das zocas (1948), A árbore (1948), O redondel (1951), Auto do prisioneiro (1969) e Os xefes (1980).

Libros e autores galegos: século XX. A Coruña: Fundación Pedro Barrié de la Maza, Conde de Fenosa, 1982, 416 pp.

Segundo volume dos dois projectados para a obra cujo volume primeiro apareceu em 1979. Na "Nota liminar" (pp. 5-7) o autor adverte: "Do moito disperso que sobre a materia podía arrecadarse, parecéu conveniente espigar o que segue, o que en certo xeito cabe contemplar como un complemento da Historia da literatura galega contemporánea" (p. 5). Inclui um conjunto de 97 de trabalhos, 
de diversa extensão, distribuídos em secções, correspondentes a autores ou a épocas, em ordem cronológica.

A gente da Barreira e outras histórias. Santiago de Compostela: Follas Novas, 1982, 168 pp.

Primeira compilação de obras narrativas. Depois de uma "Nota editorial" (p. 5), reedita-se, linguisticamente revisto, o romance $A$ gente da Barreira (pp. 7-133), publicado por primeira vez em 1951, e seguidamente, sob a rubrica geral "Outras histórias" (pp. 133-fim), os seguintes relatos, todos eles já publicados anteriormente: "As pitas baixo a chúvia", "Os tumbos", "A cegoña" e "Aos amores serodios".

Da fala e da escrita. Ourense: Galiza Editora, 1983, 140 pp.

Colectânea de 30 trabalhos diversos, de natureza prevalentemente linguística.

Letras galegas. A Corunha: Associaçom Galega da Língua (AGAL), 1984, 349 pp.

Colectânea de 44 estudos, de variada índole e extensão, de temática linguística ou literária.

Narrativa completa. Sada: Ediciós do Castro, 1984, 240 pp.

Segunda compilação de obras narrativas. O "Limiar" (pp. 9-12) explica a composição da obra: aos cinco relatos já publicados em A gente da Barreira e outras histórias (1982), incorporam-se aqui dois mais: "O señores da Pena" e "O lar de Clara”, escritos havia já tempo mas não publicados.

Cantigas de amigo e outros poemas (1980-1985). A Corunha: Associaçom Galega da Língua (AGAL), 1986, 197 pp. ("Portada e ilustraçons: Felipe Criado").

Novo poemário, em elegante edição ilustrada. Em total 62 poemas; alguns deles foram já publicados isoladamente.

La fuerza pública en la Universidad de Santiago y otros escritos escolares (19301933). Documentos para a historia contemporánea de Galicia, 33. Sada: Ediciós do Castro, 1987, 164 pp.

Recolhe um total de 9 trabalhos publicados originariamente entre 1930 e 1933. Vão precedidos de um "Prólogo" em castelhano (pp. 7-14), datado "Santiago de Compostela, 26 de febrero de 1986", e seguidos de um "Índice Onomástico". Ademais da segunda edição de La fuerza pública en la Universidad de Santiago 
(1931), pp. 15-83, agora completado com um "Epílogo a esta segunda edición” (pp. 84-86), contém outros 8 trabalhos menores publicados entre 1930 e 1933.

Scórpio. [Santiago de Compostela]: Sotelo Blanco, 1987, 398 pp.

Romance histórico, em grande medida autobiográfico. A segunda edição, idêntica à primeira, apareceu em janeiro de 1989.

Escritos sobre Castelao. A Biblioteca do Professor. [Barcelona]: Sotelo Blanco, 1989, 310 pp.

Colectânea de 24 estudos diversos em torno à figura de Castelao (vida e obra), alguns deles não publicados anteriormente, mais um epílogo, intitulado "Envio".

Estudos e ensaios sobre literatura galega. Sada: Ediciós do Castro, 1989, 336 pp. Inclui, apresentados por uma "Nota liminar" (p. 5) datada "Santiago de Compostela, 23 de Março de 1988”, 38 trabalhos, de natureza e extensão variadas, distribuídos em secções que correspondem à ordem cronológica.

Reticências... (1986-1989). Vento que zoa. [Barcelona]: Sotelo Blanco, 1990, $168 \mathrm{pp}$.

Último livro de poemas de Carvalho. Preparado para publicação pelo próprio Carvalho nos últimos meses da sua vida, saiu à luz já depois da morte do autor, mas ainda nesse mesmo ano.

Do galego e da Galiza. Estudos e investigacións. [Barcelona]: Sotelo Blanco, 1990, $242 \mathrm{pp}$.

Colectânea de 27 estudos dispersos de índole prevalentemente linguística. Saiu à luz pública pouco depois da morte do autor, tal como ele o deixara disposto para publicação.

Umha voz na Galiza: artigos de jornal (1933-1989). Estudios e investigacións. [Barcelona]: Sotelo Blanco Edicións, 1992, 336 pp. Presentación de C. Blanco.

Colectânea de 101 artigos de imprensa, apresentados por uma breve introdução de Carmen Blanco ("Presentación", pp. 7-12). Ainda que o livro saiu à luz pública dois anos depois da morte do autor, foi ele mesmo, segundo nos informa a apresentadora, quem organizou a obra e lhe deu título: "el foi quen seleccionou os artigos, dispuxo a orde, estableceu o texto, deu título ao conxunto e decidiu que eu o prologase" (pág. 9). São em total 101 artigos, 
publicados entre 1933 e 1989 em diversas publicações periódicas (El Pueblo Gallego, Faro de Vigo, Diario de Galicia e A Nosa Terra, as quatro de Vigo; La Voz de Galicia, de A Corunha; El Correo Gallego, de Santiago; La Región, de Ourense). Tratam temas de índole diversa: lingüística, literária, cultural ou mesmo política. Estão numerados e ordenados cronologicamente.

\section{ACTIVISMO SÓCIO-CULTURAL}

O seu labor nestes anos, como sempre fora, não se limitou unicamente a actividades de escritório: também desenvolveu acções públicas e compartiu o activismo cultural de diversos colectivos. Assim, acompanhou com entusiasmo desde o primeiro momento a fundação da AGAL (Associação Galega da Língua), que se converteria nos anos sucessivos no seu círculo de companhia mais querido, por ele considerado como uma espécie de testamenteiro dos seus ideais linguísticos (Henríquez 1992). E fez parte do conselho de redacção da revista Agália, que seria o seu principal órgão de expressão nestes anos, como antes o fora a revista Grial. Ele foi quem co-presidiu os dois primeiros congressos da língua organizados pela AGAL em 1984 e 1987 respectivamente.

Igualmente participou nos congressos em torno às figuras de Rosalia e de Castelao, celebrados em Santiago, respectivamente, em julho de 1985 e em 1986. E proferiu conferências em muito diferentes foros, viajando por toda a Galiza e por fora dela. Como simples e limitada amostra, podemos lembrar algumas actividades de um pequeno lapso de tempo: o verão de 1985:

- Em junho viaja à Alemanha para participar no I Colóquio sobre Cultura e Língua Galegas, celebrado na universidade Ludwig Maximilian de Munique?2.

- Em julho participa em Santiago de Compostela no congresso sobre a vida e obra de Rosalia Castro, coincidindo com o centenário da data do falecimento da escritora.

- Em agosto de 1985 viaja, por segunda (e última) vez na sua vida, a Buenos Aires para participar, nos dias 22-24, nos diversos actos do II Simpósio Internacional da Língua Galego-Portuguesa, celebrando o centenário do falecimento de Rosalia Castro 3 .

Outras amostras de actividades, colhidas ao azar entre muitas outras:

2 Sobre este I Colóquio sobre Cultura e Língua Galegas, celebrado nos últimos dias de junho de 1985, pode ver-se a breve nota informativa "I Colóquio sobre Língua e Cultura Galega", Agália, 3 (1985), 363. Uma resenha mais pormenorizada, redigida por Carlos Durão - um dos participantes no Colóquio -, em Renovação, 3 (1991), 13-14.

3 Véjase "II Simpósio Internacional da Língua Galego-Portuguesa", Agália, 4 (1985), 480-481. 
- Em 3 de dezembro de 1985 participa em Vigo na mesa redonda organizada pela AGAL:

Em Vigo, o dia 3 de Dezembro, na Casa da Cultura, celebrou-se umha mesa-redonda, em que participárom as professoras Aurora Marco Lôpez e Maria do Carmo Henríquez Salido com o professor Carvalho Calero. Falárom dos objectivos, trabalhos e actividades da AGAL desenvolvidas desde o ano da sua criaçom (Outubro de 1981) até o momento presente. [...] Ricardo Carvalho Calero, na sua dissertaçom, situou o reintegracionismo dentro das teses defendidas polos mais importantes vultos da Filologia Románica, nomeadamente Menéndez Pidal, e dentro da história do nacionalismo galego, fazendo referência, mais específicamente, à obra de A. Rodríguez Castelao Sempre en Galiza e à carta dirigida a Cláudio Sánchez Albornoz, em que se insere o seu desejo de que «el gallego se acerque y confunda con el portugués». Noticiário da AGAL. Agália, 4 (1985), 480.

- Ainda em 25 de fevereiro de 1988 fez em Santiago a apresentação de um livro de homenagem ao poeta José Maria Díaz Castro, editado pela associação cultural Xermolos de Guitiriz ${ }^{4}$.

\section{O COMPROMISSO COM A LÍNGUA}

As suas conviç̧ões sobre a necessidade e a urgência da reintegração do galego na Lusofonia foram ganhando cada vez mais decisão nestes anos, tanto no nível teórico como no prático.

A evolução sócio-linguística era cada dia mais alarmante e dramática: nem a declaração oficial do galego como língua cooficial na comunidade e o uso conseguinte em ambientes oficiais, nem a introdução do galego no ensino obrigatório, nem a criação de uma rádiotelevisão em galego pareciam não já invertir, mas nem sequer deter nem mesmo atenuar a progressiva perda de falantes iniciais.

No nível teórico pensava que era preciso ir introduzindo prudentemente a denominação, para a língua da Galiza, de "língua portuguesa", pois a denominação comum e habitual de "língua galega" mostrava-se enganosa tanto para os galegos como para os foráneos, máxime quando alguns na Galiza entendiam sob essa denominação uma língua independente da portuguesa.

À vista da evolução da Real Academia Galega naqueles anos, e da sua conformação, chegou à conclusão de que era preciso criar uma nova academia que

4 Véjase a notícia do acto em La Voz de Galicia (ed. de Santiago), 26/II/1988, 29. 
mostrasse no seu próprio nome a pertença da Galiza ao mundo lusófono e que mantivesse relações sistemáticas com os organismos que se ocupam da língua portuguesa. Esse projecto tardaria ainda alguns anos em realizar-se, mas finalmente surgiria como Academia Galega da Língua Portuguesa, fundada em Santiago em 2008.

No labor de reintegração da língua da Galiza ao âmbito lusófono propugnava a adaptação pedagógica aos diferentes ambientes e destinatários, segundo a "receptividade social". Por isso usava, com plena consciência, diferentes ortografias segundo as circunstâncias e comentava com humor o escândalo que esta praxe provocava em alguns. Mas não deixava de advertir que esse avance não podia não já deter-se ou adiar-se ad calendas graecas, mas nem sequer atrasar-se, porque as circunstâncias sócio-linguísticas não permitiam demoras.

E manifestou repetidamente que, no que se refere à ortografia, a meta não podia ser outra que uma substancial unidade com o restante mundo lusófono, sem prejuízo das peculiaridades propriamente linguísticas (fonéticas, morfo-sintácticas ou léxicas).

\section{A MARGINALIZAÇÃO DO GALEGUISMO OFICIAL}

Tanto a sua personalidade científica e literária como a sua entrega generosa ao serviço da cultura galega e a atitude ética ao longo de tantos anos ganharam-lhe uma geral veneração em amplos âmbitos da sociedade galega. Desde os últimos anos 60 a finais da década dos 70 Carvalho Calero gozou na Galiza de um prestígio reservado a poucos e sempre crescente.

Porém, o debate sobre o futuro da língua da Galiza (e, conseguintemente, da sua identidade idiomática), para o qual o artigo de Rodrigues de Lapa do ano 1973 serviu de catalizador, situou Carvalho Calero em posição de alvo de uma crescente incompreensão de alguns, que se foi transformando em aberta hostilidade, mesmo por parte de alguns dos seus antigos amigos de Galaxia.

Não devemos silenciar as injustiças que sofreu neste período e bem está deixar constância de tudo isso para a história da sua vida, porque, paradoxalmente, são feitos e experiências que engrandecem a sua figura como pessoa e a estatura da sua dignidade moral. Contudo, seria injusto dar muito relevo a esses assuntos de dimensão mais pessoal, porque esses acontecimentos não são os que merecem ser lembrados para a história geral da cultura galega. Ele próprio, apesar do sofrimento que inevitavelmente lhe produziram, esforçou-se por viver constantemente por cima disso. Afinal, na biografia de Carvalho o que tem verdadeira importância para a cultura galega, e nomeadamente para a nossa língua, é a sua produção escrita, que foi muito rica também nesse decénio final. 
Podemos situar o início do distanciamento com o grupo de Galaxia (Ramom Pinheiro, Garcia-Sabell, Fernández del Riego...) nas reacções produzidas na Galiza pelo artigo de Rodrigues Lapa. Como mostra a réplica que publicou ao artigo de Lapa, Ramom Pinheiro não compreendeu o sentido das suas reflexões e creu ver nessa proposta algo assim como uma "emenda à totalidade" do labor do galeguismo do pós-guerra, e, portanto, de Galaxia 5 .

Ora, sabe-se por testemunho do próprio Carvalho que Pinheiro, ademais de escrever essa réplica pública a Lapa, esforçou-se por suscitar também respostas por parte de outros escritores galegos, quer fossem privadas (em cartas pessoais a Lapa), quer preferentemente públicas. Também falou neste intuito com Carvalho Calero, quem lhe respondeu que, antes de rejeitar a proposta de Rodrigues Lapa, a cultura galega e o galeguismo deveria analisar com rigor a situação para ver se Lapa tinha razão. Para Pinheiro (e para o seu círculo mais próximo) esta atitude de Carvalho significava uma desautorização e foi interpretada como uma ofensa. E a partir desse momento começaram a desconfiar da "fidelidade" de Carvalho e logo a acusá-lo particularmente de pouco menos que traição não só à empresa comum do galeguismo de Galaxia mas também à própria cultura galega, e a marginalizá-lo para evitar que pudesse propagar as suas ideias ou "contagiar" outros com elas, sobretudo gente nova.

Desde o mesmo momento em que Carvalho se jubilou (1980) algumas personalidades destacadas do que podemos considerar como "galeguismo oficial" adotaram uma atitude abertamente contrária a Carvalho e ao seu legado linguístico. Em alguma gente deu-se mesmo por vezes uma agressividade que ultrapassa os limites não já da cordialidade ou da discussão científica mas mesmo da simples educação.

No verão de 1980 Fernández del Riego publicou um artigo no jornal Faro de Vigo em que propunha uma homenagem a Carvalho. Em carta de resposta, datada em Santiago em 4 de setembro, Carvalho mostrava a sua firme oposição a essa proposta e, entre outros motivos, explicava-lhe:

por se é preciso que o saibas, direi-che que notícias aquí chegadas sobre plans dese tipo, atoparon por parte de quen pode falar en nome da Faculdade, a resposta que era de esperar, e que me lembra que non podo ofender aos que desexan que non rompa enteiramente a miña vida de relación coa Universidade (Carballo 2006, pp. 560-561).

5 Lembro a decepção de Lapa, que ele próprio me manifestou, ao ver que Pinheiro não entendera a sua proposta de futuro, nem parecia consciente da gravidade real da situação linguística galega, e respondera com considerações que não vinham ao caso da problemática comentada. 
Reflexos desta situação podemos vê-los também nas actas do colóquio sobre o galego celebrado no mês de novembro de 1980 em Tréveris (Alemanha). Podemos lembrar algumas das manifestações relativas a Carvalho nesse colóquio:

é pena, e esto é o mais grave, que o primeiro catedrático de Lingüística e de Literatura Galega que tivemos en Galicia e na Universidade de Santiago, o señor Carballo Calero (hoxe xa xubilado), en vez de defende-lo galego, crease ultimamente unha normativa portuguesa [...]. Empezou explicando na Cátedra o galego e despois no mesmo ano ou en anos sucesivos, foi variando constantemente astra chegar a unha normativa totalmente artificial, absurda, que non hai por onde tomala, utilizando esa grafía portuguesa e tamén palabras portuguesas no lugar das galegas. Polo tanto, hai esa normativa da Cátedra de Lingüística e de Literatura, que fixo un mal gravísimo á lingua galega, con esta posición tan absurdamente portuguesa [...]. Hai a Xunta de Galicia e neste momento vai chegar á conclusión de que nada de lusismo, nada de portuguesismo, senón galego (Kremer e Lorenzo 1982, pp. 247-248) ${ }^{6}$.

o 30 de Setembre [de 1979] ó constituirse diante do Ministro de Educación de Madrid a Comisión do Decreto de Bilingüismo [...] tiña á miña dereita, e non é ningunha ironía, a Carballo Calero, catedrático xubilado hai poucos días e que estaba ó frente dunha Comisión de Lingüística, que el realmente tiña a intención, que logo levou case case á realidade, de lusitanizar astra onde fose posible algo mais que o sistema gráfico do galego. [...] sucedeu en Abril [de 1980]. Os profesores quedaron estupefactos e agora, hai, por exemplo, dous libros de texto totalmente portuguesistas [...] Esto é dunha enorme gravedade (Kremer e Lorenzo 1982, p. 241) ${ }^{7}$.

Carvalho fora convidado pelos organizadores alemães a participar neste colóquio mas renunciou a assistir, pelas razões que ele expunha a Rodrigues Lapa em carta datada em 1 de outubro de 1980 em Santiago:

Tampouco eu penso ir a Tréveris, como nom surja umha circunstáncia de última hora que me aconselhe modificar a minha decisióm. Nom porque creia que os antilusistas dominarám a escena (pois a presenza do reintegracionismo ali oporia sérios obstáculos à sua propaganda), senóm porque o ambiente persoal, o clima

\footnotetext{
6 São palavras do professor Ramón Lorenzo, que acabava de ocupar a cátedra universitária que Carvalho deixara vacante ao jubilar-se.

7 São palavras do professor Alonso Montero.
} 
reinante entre os participantes galegos, me resultaria dificilmente respirábel como consecuéncia das posicións que se registarom ultimamente entre nós perante os problemas plantejados (Marques 1997, p. 382).

Por testemunho de Luciana Stegagno e de Celso Cunha sabemos que este colóquio de Tréveris deixou tanto neles como em outros filólogos estrangeiros (Walter Mettmann, Joseph Piel, Harri Maier...) uma enorme decepção científica perante o espectáculo que presenciavam do domínio político da ideologia desmembradora do idioma, e o receio, quando não o convencimento, de que nessas circunstâncias o futuro que se podia prever para a língua da Galiza era mais que incerto.

A atitude de desqualificação contra Carvalho Calero contrasta com o tom sereno, respeitoso e razoado dos escritos com que o próprio Carvalho expunha as suas ideias, baseadas unicamente em razões de natureza científica e de preocupação pelo futuro linguístico da Galiza.

Essa confrontação em torno à orientação futura da nossa língua complicou-se sobretudo por causas de natureza política: paradoxalmente, o estabelecimento, por primeira vez, de um poder político autónomo galego - pelo qual Carvalho, como nacionalista, sempre advogara desde a mocidade - veio introduzir um elemento de distorsão no movimento cultural galego ${ }^{8}$.

O governo galego, depois da dissolução da Comissão Linguística que Carvalho presidira, encaminhou a política linguística galega pela via do isolamento a respeito da Lusofonia. O golpe mais grave neste processo foi a derrogação das normas linguísticas elaboradas por aquela comissão, que intentaram estabelecer uma concórdia entre as duas tendências.

Nesta situação não é de estranhar que a postura convencida e decidida de Carvalho em favor da reintegração linguística galego-portuguesa torcesse a lealdade dalguns para o velho mestre, mesmo dalguns antigos amigos. $O$ facto é que, por esta razão, a partir de então Carvalho viu-se relegado e marginalizado, e até desprezado e caluniado de diversos modos, sobretudo desde as distintas instâncias do poder político-cultural9.

8 Sobre a implicação política nas decisões linguísticas é útil a informação oferecida por Victoria Armesto acerca de uma reunião-jantar na casa de Augusto Assía e Victoria Armesto em agosto de 1981 em Janceda, na qual participaram Manuel Fraga Iribarne, Gerardo Fernández Albor, Constantino García e Ramón Lorenzo: "fue el 28 de agosto de hace dos años cuando se celebró aquella comida en la casa de Xanceda apareciendo Manuel Fraga en un pequeño coche que conducía su hija Pipo. Con Fernández Albor llegaron también de Santiago los profesores Constantino García y Ramón Lorenzo, máximas autoridades en lengua gallega. / Era un día caluroso y pesado. No se habló en absoluto de política y sólo se trataron temas universitarios y culturales siendo el entendimiento entre el profesor Fraga y el resto de los profesores y doctores muy armonioso. (Armesto 1983, p. 15).

9 Eis o testemunho do professor José Luís Rodríguez, que esteve próximo a ele nesses anos: "D. Ricardo sabia-se incompreendido polo seu círculo de colegas e amigos, de Galáxia e da Academia, aos quais 


\section{DOIS TRAUMAS}

Talvez não seja muito exacto falar de "traumas" na personalidade de Carvalho Calero, à vista da resistência e da admirável firmeza de ânimo com que suportou as repetidas adversidades da sua biografia, desde os tempos da infância. Mas se tomarmos o conceito de trauma com um sentido mitigado como experiência que produz um sofrimento duradeiro, deveremos anotar para este período final da sua vida dous traumas que abalaram o seu espírito (provavelmente mais sensível nestes anos da ancianidade) e que lhe produziram amargura: um primeiro trauma de nível pessoal e um segundo trauma de nível colectivo.

Em primeiro lugar, houve um trauma no nível pessoal das relações com os seus velhos amigos da Editorial Galaxia. Galaxia era como a alma da consciência cultural da Galiza, até o ponto de que podia considerar-se justificadamente como "o galeguismo oficial" e os homens que a organizaram e a mantiveram durante os 30 anos transcorridos de 1950 a 1980 constituíam para ele como o ninho familiar, como uma segunda família, onde sentia o calor da fraternidade e para a qual não duvidou em oferecer todo género de sacrifícios. Os epistolários com Ramom Pinheiro ou com Fernández del Riego são como um espelho dessa convivência fraternal.

Desde a segunda metade da década dos 70 , e mais claramente nos 80 , viraram-se as tornas. Carvalho passou a ser para o "galeguismo oficial" uma pessoa suspeitosa de traição ao grupo. O ostracismo, a marginalização e até o menosprezo a que foi submetido nesses anos tem muitos acontecimentos, de menor ou maior transcendência, que os que estávamos perto dele neste tempo pudemos seguir pelo seu próprio testemunho - quando não eram públicos e notórios...

Dessa dolorosa experiência de Carvalho soube pessoalmente, por testemunho dele, de vários pequenos acontecimentos.

A partir desse momento sentiu que ficava fechada para ele a publicação na Editorial Galaxia e até na revista Grial, fora de alguma reedição e algum artigo de circunstâncias. Já em 1978 há indícios de que ele temia que a sua colaboração em Grial não fosse bem recebida e duvidava da oportunidade de seguir enviando contributos. Acompanhando uma colaboração para Grial que envia a Fernández del Riego diz-lhe: "No sucesivo, se che mando máis colaboración," (Carballo 2006,

resolveu nom acompanhar na aventura político-cultural de «Realidade Galega» [...]. Nom acompanhou o seu trânsito para a política, pilotado por R. Piñeiro, cujo objetivo parecia ser galeguizar os partidos de corte estatal; por sua vez, os seus antigos correligionários, com García-Sabell, presidente da Real Academia Galega e delegado do Governo ao mesmo tempo, à cabeça, vírom como inoportuna ou mesmo disparatada a deriva cara o reintegracionismo, tanto teórico como prático, assumida por Ricardo Carvalho Calero. Este, umha vez jubilado da cátedra, ficou isolado da oficilialidade [...], fadado para a invisibilidade" (Torres 2020, pp. 91-92). 
p. 554). Em carta de 5 de abril de 1982 a Fernández del Riego fala novamente da sua presença em Grial:

Vexo que continua figurando o meu nome no Consello de Redacción; mais se non se me envia a revista nen rexistro nen ningun outro indício de que se me considera efectivamente no mesmo, podo pensar se aquela persisténcia é debida simplemente a inadverténcia. (Carballo 2006, p. 562).

Um ano mais tarde, em maio de 1983, novamente em carta a Fernández del Riego voltava a falar de Grial:

Se algun dia deixas de ocupar-te de Grial, rogo-che que mo comuniques, para que eu poda reflexionar a propósito da actitude que hei de adoptar no que se refere à miña colaboración na revista. (Carballo 2006, p. 566).

Que eu saiba não chegou a dar-se um rejeitamento explícito por parte dos responsáveis de Galaxia. Mas foi assim porque ele, sempre propenso a não provocar conflictos, bem consciente de qual era a posição que Galaxia assumira na suas publicações a respeito da normativa linguística, evitou dar ocasião a isso.

Em quanto à atitude da editorial Galaxia e da revista Grial, fui testemunha (e até em certo modo protagonista) de um pequeno feito que resultou determinante para Carvalho.

Quando no verão de 1983 se publicou o seu livro Da fala e da escrita, como eu conhecia bem o seu conteúdo por tê-lo transcrito, tendo observado que os últimos livros de Carvalho não foram resenhados em Grial como antes eram, decidi elaborar eu próprio uma resenha, de carácter informativo e objectivo. Antes de enviá-la, dei-lha a ler e ficou satisfeito com ela. Estava redigida na mesma normativa reintegracionista usada no livro. Mandei-a então a Fernández del Riego e, algum tempo depois, recibi em resposta uma carta sua, em que me comunicava que a resenha era interessante, mas que sentiam não poder publicá-la porque não seguia a "normativa oficial". Ensinei a carta a Carvalho e ficou impressionado: "Está claro que já não podemos contar com Galaxia", disse, profundamente entristecido. Ficamos então em passá-la a normativa portuguesa padrão, dando por suposto que Grial não deixaria de publicar textos portugueses como vinha fazendo desde os seus inícios. Com esta explicação enviei de novo a resenha e foi finalmente publicada (Montero 1984). Mas o pequeno incidente deixou clara a atitude de Galaxia e em diante Carvalho nunca pretenderia suscitar nenhum conflicto.

Desse modo Galaxia deixa de ser a sua editora. A partir desse momento os seus livros estão publicados em Ediciós do Castro, em Sotelo Blanco ou nas entidades 
reintegracionistas, e os seus artigos de índole erudita aparecem preferentemente na revista Agália.

Nas Ediciós do Castro publicou a reedição, revista, da sua produção literária dos anos precedentes (poesia, narrativa, teatro), como bem lembrou Isaac Díaz Pardo:

Polo ano 79 veu por Sargadelos e ofreceunos publicarlle os libros Pretérito Imperfecto, Futuro Condicional e o Teatro completo. No 82 tróuxonos Afonso Xo Sabio, Cantigas de amor, de escarño e de louvor, e a Narrativa Completa. No 86, dounos, pra a serie Documentos, La Fuerza Pública en la Universidad de Santiago y otros escritos escolares. [...] E xa no 88 entregounos os Estudos e Ensaios sobre Literatura Galega. [...] Finalmente, no 93 Claudio Rodríguez Fer tróuxonos a Poesía perdida de Ricardo Carvalho Calero. E nós sentímonos moi honrados de ter no noso catálogo oito libros do ilustre profesor, poeta, narrador, lingüísta, e moitas cousas máis, aínda que desta sorte nosa poidan tirarse outras razóns. (Díaz Pardo 2002, p. 300).

Também o editor Sotelo Blanco, que publicou várias obras de Carvalho entre elas, duas que são talvez as melhores da sua produção literária: o romance Scórpio (1987) e poemário Reticências... (1990) -, lembrou como chegou a editar essas obras:

Corría o ano 1986 [...] como novo editor, pensei que debía empezar a marcar unha liña de publicación na que coubese a pluralidade que se manifestaba na realidade de entón. [...] Como nos sectores enfrontados aos lusistas falábanme mal de don Ricardo, pensei que o mellor era coñecelo. [...] no Derbi de Compostela, logo de horas de parola, decateime de que acababa de coñecer un home encantador. Faloume dos problemas aos que se enfrontaba para poder editar, xa que non era da corda dos do monopolio cultural de Galicia. [...] dende entón non só decidín que lle publicaría as obras que me presentase, senón que pasamos horas conversando á vez que se comezaba a forxar unha boa relación persoal. (Sotelo 2020, p. XIII).

\section{CARVALHO CALERO E A RAG}

Com a Real Academia Galega Carvalho Calero desenvolveu uma longa e intensa relação durante muitos anos. Podemos começar lembrando como na sua Historia da literatura galega contemporánea (1975), ao apresentar uma introdução ao renascimento literário contemporâneo (a "época que se estende desde a publicación dos Cantares Gallegos ate a morte de Pondal”, p. 129), dedica uma secção a historiar o 
nascimento da Academia, com os seus antecedentes. E não deixa de citar o discurso inaugural de Murguia, onde dizia:

no se borra tan fácilmente en los labios que la mamaron la lengua que habló este pueblo durante más de diez siglos; que es la que hablan y entienden cerca de tres millones de gallegos, diez y ocho millones de habitantes en Portugal y sus dominios, doce en el Brasil. (Carballo 1975, p. 139).

O académico Xosé Luis Axeitos (2020) ofereceu informação sobre o expediente de Carvalho Calero conservado no arquivo da Real Academia Galega. Axeitos declara que "algúns datos cobran hoxendía especial relevancia debido aos moitos anos de postergación que padeceu por parte da Real Academia Galega" (2020, p. 6).

Em 1951, pouco depois de publicar-se A xente da Barreira, Carvalho é nomeado membro correspondente: "o seu expediente comeza cando é nomeado «Correspondiente» no ano 1951 a instancias de Vales Villamarín, Otero Pedrayo, José Luis Bugallal e Leandro Carré" (2020, p. 6). O próprio Carvalho contou que não chegou a saber que fora nomeado correspondente até anos mais tarde:

Eu era correspondente xa da Académia, cando fun designado numerário. Levava vários anos de correspondente, pero non o sabia. [...] Mas cando se me designou numerário, puxo-se de manifesto que xa fazia vários anos que se me nomeara correspondente, pero o secretário ou o presidente da Académia entregara a comunicazón dirixida a min, na que se me participava a designazón, a don Ramón Otero Pedrayo, que seguramente fora o propoñente, e don Ramón Otero Pedrayo metera a comunicazón no bolso e non a tirou até que anos depois fun nomeado numerário. [...] non chegou até min a comunicazón por unha distraczón de don Ramón Otero Pedrayo. (Fernán-Vello e Pillado 1986, p. 144).

Foi eleito membro numerário na sessão académica de 31 de março de 1957, com 27 sufrágios favoráveis. O seu ingresso realiza-se um ano mais tarde, em 17 de maio de 1958, com um discurso sobre as fontes literárias de Rosalia. Desde esse momento nos seus epistolários podemos seguir o seu constante interesse pela renovação da Academia e pelos seus diversos trabalhos e actos. Também é oportuno lembrarmos o seu trabalho de investigação histórico-literária no arquivo e na biblioteca da Academia.

Aqui importa-nos agora centrar-nos no decénio final da sua vida. Neste tempo Carvalho ficou afastado da vida da RAG por causa do caminho que a 
Academia empreendeu desde o momento em que se inclinou a assumir as propostas normativas do ILG. Naturalmente, não foi nunca expressamente excluído das reuniões académicas. Mas ele entendeu que, dado que as suas ideias ao respeito estavam claramente formuladas em repetidas intervenções escritas e declarações orais públicas, a RAG, ao prescindir dele, não desejava o seu contributo, e que a sua presença resultaria inoportuna - ou, melhor dito, importuna.

Houve um acontecimento que, embora totalmente alheio a Carvalho, ajuda a compreender algo da hostilidade que no galeguismo oficial (e, neste caso concreto, especialmente no círculo directivo da RAG) se gerou contra ele. Pode ser aqui uma boa ocasião para esclarecer este feito, que conheço bem porque, sem procurá-lo, vi-me implicado directamente aí.

No dia 3 de julho de 1982 aprovou-se na sede da Real Academia Galega, na Corunha, a normativa linguística que se acordara reservadamente nos meses precedentes com o Instituto da Lingua Galega. Na comissão (de funcionamento mais teórico do que real) que preparara essa normativa não se incluíra Carvalho, apesar de que a normativa académica vigente até esse momento fora elaborada sob a sua responsabilidade principal.

Duas semanas antes desse dia, com data 18 de junho, o presidente da Academia, García-Sabell, enviara por correio a todos os académicos um avultado fascículo de fólios com o texto da normativa. Este trabalho ia apresentado por uma carta em que se convocava os académicos para essa "Xunta Extraordinaria" que trataria como "Asunto único: Estudo da ponencia sobre da unificación das normas ortográficas e morfolóxicas do galego, entre a Real Academia Galega e o Instituto da Lingua Galega". E seguia esta advertência: "Rógase que este borrador non pase aos meios de comunicación nin se lle dea publicidade mentras non teña lugar a Xunta Estraordinaria".

Ora, aconteceu que, contra a reserva aqui solicitada aos académicos, nos próximos dias fez-se pública esta carta e, em geral, o conteúdo da normativa que se ia tratar, a qual recolhia fundamentalmente as propostas que já vinha defendendo o Instituto da Lingua Galega desde a edição das Bases. A consequência dessa filtração da notícia foi uma série de declarações críticas, tanto ao segredo como à própria normativa em si, que foram aparecendo nos jornais dos dias seguintes. E na própria tarde da reunião juntou-se à porta da Academia uma pequena manifestação de protesto, de umas 30 pessoas segundo a informação da imprensa do dia seguinte.

$\mathrm{Na}$ Academia havia naquele momento vários membros que tinham manifestado publicamente a sua simpatia reintegracionista: ademais de Carvalho, podiam integrar-se nessa tendência Jenaro Marinhas, Valentim Paz-Andrade, Enrique Vidal Abascal e talvez algum outro. Poderia, pois, suspeitar-se que entre estes se 
encontraria o que decidiu não ater-se à reserva solicitada pelo presidente. E, entre todos eles, especialmente Carvalho. Ademais, o feito de que esse documento fosse divulgado nos dias seguintes pela AGAL e pela AS-PG, duas associações que estavam cordialmente ligadas a Carvalho, era um indício mais para atribuir-lhe a filtração desse texto.

A verdade é que nem Carvalho nem nenhum dos académicos citados tinha nada que ver com o caso. Mas nos dirigentes da Academia surgiu espontaneamente o convencimento de que fora ele e consideraram o feito como uma falta à confiança da instituição. Contou-me o próprio Carvalho que, quando na ocasião seguinte coincidiu num acto público com García-Sabel e com a sua mulher, acercou-se para saudá-los cordialmente, como sempre fazia, e achou neles uma manifesta resistência. "Agora já sei - comentava entristecido - que de agora em diante já não podo permitir-me essa familiaridade...”.

Foi o académico Henrique Chao Espina (Viveiro 1908 - A Corunha 1989) quem, por própria iniciativa, me fez conhecer o envio que acabava de receber da Academia. Estava irritado tanto pelo processo em que se decidira a normativa como pela reserva que agora se pedia sobre o assunto. Como ele, embora residisse na Corunha havia anos, fora sacerdote da nossa diocese de Mondonhedo, tínhamos certa relação desde havia tempo. Era fervoroso simpatizante de Portugal e da cultura portuguesa e fora professor de português; até publicara uma gramática portuguesa. Na verdade, o seu conhecimento da normativa linguística portuguesa era, por assim dizer, "por aproximação", não muito rigoroso. Como dixe, ele era cultivador e até promotor do relacionamento cultural com Portugal, mas, que eu saiba, nunca se manifestara publicamente a favor do reintegracionismo linguístico galego-português; porém, privadamente tinha-me dado os parabéns por algum artigo meu nesse sentido.

Quando recebeu o envio da nova proposta normativa, telefonou-me e fez-me conhecer o seu malestar; e dizia-me que os novos tínhamos que reaccionar perante o que ele considerava um atropelo para a língua e para a Academia. E ofereceu-se a facilitar-me uma fotocópia do texto. Lembro que lhe perguntei se queria que se mantivesse em segredo o seu nome e disse-me que nada disso e que ele estava disposto a falar sobre o caso à imprensa se estiverem interessados na sua opinião. Ficamos, pois, em que nos dias seguintes, quando eu tivesse tempo, passaria pela Corunha e faríamos as fotocópias.

Entretanto, também o bispo Araújo, igualmente académico, recebeu o envio. Compartíamos domicílio na residência da Domus Ecclesiae de Ferrol, e pouco depois informou-me que lhe chegara um "longo texto" da Academia com a proposta de normativa linguística e com o estranho rogo de que não se tornasse público. Comentei-lhe então a chamada telefónica de Chao Espina e como eu 
ficara em ir recolher a fotocópia do texto na Corunha, e disse-me que não fazia falta que viajasse à Corunha pois dava-me ele o seu, para que fizesse com ele o que quiser. Fotocopiei-o e devolvi-lho. E telefonei a Chao Espina informando-o de que já não precisava ir à Corunha.

A AG-LP fez logo uma edição de um pasquim com a reprodução da carta, e assim foi como se divulgou a notícia e se suscitaram as reacções.

De maneira que Carvalho Calero permaneceu totalmente alheio ao caso.

Desde esse momento parece que, na Academia, só Ramón Pinheiro intentou manter algum contacto, epistolar, com Carvalho sobre o tema da língua, e está publicada a longa resposta, explicativa e justificativa, de Carvalho.

Porém, contrariamente ao que alguns têm escrito, Carvalho nunca se demitiu da Real Academia Galega ${ }^{10}$.

\section{HOMENAGENS}

Precisamente porque havia uma consciência comum da injustiça que o galeguismo oficial exercia contra o velho mestre, Carvalho viu-se agasalhado pelo carinho de muitos amigos verdadeiros, de muitos alunos e admiradores. Por isso nos últimos anos da sua vida abundaram as homenagens à sua pessoa.

Assim, em dezembro de 1981 a Sociedade Cultural Medúlio, de Ferrol, organizou uma semana de actos em sua honra, com várias conferências, concluindo com uma do próprio Carvalho, as quais se editariam depois num opúsculo. Com essa ocasião colocou-se na sua casa nativa, no núm. 51 da rua de São Francisco, uma placa com inscrição comemorativa do nascimento.

Pouco depois, em maio de 1982 várias entidades culturais galegas dedicaram-lhe na Corunha uma nova homenagem, em certo modo como desagravo perante o ostracismo a que se via submetido por parte do galeguismo oficial a causa das suas ideias reintegracionistas ${ }^{11}$.

10 Em relação com a figura de Carvalho Calero, sim apresentou a sua renúncia o escritor Jenaro Marinhas del Valle: apenas uns dias depois do falecimento de Carvalho, dirigia à Real Academia Galega uma carta em que comunicava a sua renúncia como membro numerário da instituição. Desaparecido Carvalho Calero, dizia, quebrara-se o fio que ainda o podia manter afectivamente ligado ao organismo, do qual, desde a aprovação da normativa de 1982, mantivera "uma distáncia sem chegar à separaçom total mentres honrava a Instituiçom a figura excepcional de Ricardo Carvalho Calero. Quebrado agora, bem dolorosamente para mim, esse fio que à Academia me prendia, deixo vacante um sitial que nunca ocupei gostoso e admito que sem merecimentos”. Pode ver-se o texto da carta em Agália, 21(1990), 115.

11 A homenagem esteve organizada pelas entidades seguintes: Agrupación Cultural O Facho, Asociación Cultural Alexandre Bóveda, Associaçom Galega da Língua, Asociación Sócio-Pedagóxica Galega, Ateneo da Coruña e Escola Dramática Galega. A estas aderiram várias sociedades e organismos de diferente índole. 
Posteriormente a revista $O$ Ensino dedicou-lhe um número de homenagem, com participação de numerosos colaboradores. Publicaram-se logo dois amplos volumes de Conversas com ele (aos quais há que adir outros dois aparecidos depois de Carvalho morrer), fundamentais para o conhecimento da vida e da obra de Carvalho.

Entretanto várias instituições outorgaram-lhe também honras: em 1981 a Academia das Ciências de Lisboa acolheu-o como membro correspondente, e tanto a Asociación de Escritores en Lingua Galega como a Associaçom Galega da Língua (AGAL) nomearam-no membro de honra.

No que diz respeito às suas relações com o poder político galego, Carvalho aceitou a medalha Castelao que em 1984 lhe outorgou o governo galego, mas recusou o convite pessoal (telefónico) de Filgueira Valverde, na altura membro do governo galego, para fazer parte do Conselho da Cultura Galega que acabava de instituir-se.

\section{A DOENÇA (1988)}

Passada a metade da década de oitenta, na primavera de 1988, apareceram os primeiros sintomas da doença que acabaria tirando-lhe a vida: cancro pulmonar ${ }^{12}$.

Nos primeiros tempos da enfermidade ainda realizou algumas intervenções públicas, as quais não deixavam de produzir profunda impressão no público que estava já informado da gravidade dos seus males. Mas, naturalmente, o desenvolvimento progressivo da doença e os conseguintes compromissos de natureza médica obrigaram-no a ir reduzindo a sua atividade pública ${ }^{13}$.

Foi atendido na clínica A Rosaleda, de Santiago, sob o cuidado do doutor Agustín Sixto Seco, antigo aluno seu em Ferrol. Entre a clínica e o seu domicílio na rua da Carreira do Conde achará ainda energias para continuar o trabalho quase até o derradeiro dia.

Vários poemas escritos nesses dias, e recolhidos depois no livro Reticências... (1986-1989) (1990), aparecido já postumamente, têm como fundo a experiência da doença.

12 Carvalho fora fumador e em várias fotografias pode ver-se fumando. Mas deixara o hábito de fumar bastantes anos antes, em 1969. Falando das suas relações com o escritor lucense Ângelo Fole durante a época de Fingoi, declarava: "El ia moitas veces por Fingoi. Houbo unha época en que os sábados pola tarde ou os domingos, se cadra, en que eu non saía de Fingoi, collia o seu caxado e ia até ali e se sentaba enfrente de min no meu despacho e alí estábamos falando moito tempo, fumando, porque eu entón fumaba, eu fumei até o ano 69, e el era moi fumador" (Blanco 1991, p. 45).

13 Assim, em março de 1989 teve que declinar o convite que o seu antigo aluno José Maria Dobarro lhe dirigiu por carta para assistir ao $2^{\mathrm{o}}$ Congresso de Escritores em Língua Galega, que se ia celebrar em Lugo (carta de data 13 de março de 1989, conservada no arquivo de Carvalho no Parlamento Galego, juntamente com um esboço autógrafo da resposta de Carvalho: AC 112 0042b). 
O 7 de janeiro de 1990, já muito avançada a doença, ainda viajou a Ferrol para receber pessoalmente da Câmara Municipal o título de Filho Predilecto no dia da festa de São Julião, padroeiro da cidade.

\section{FALECIMENTO (MARÇO DE 1990)}

Faleceu em Santiago no dia 25 de março de 1990. Não chegou, pois, a fazer os 80 anos, que completaria em outubro. Concluía assim "uma vida densa e austera, dedicada a trabalhar por Galiza e pola sua cultura", como acertadamente a definiu a sua filha Maria Vitória (Carvalho-Calero Ramos 1992, p. 117).

Apesar de que a gravidade da sua doença era conhecida por muitos, o falecimento produziu impressão em boa parte da sociedade galega, como recolhiam no dia seguinte os jornais da Galiza ${ }^{14}$.

$\mathrm{Na}$ tarde do dia 27 celebrou-se o funeral de corpo presente na igreja conventual de São Francisco, de Santiago, com missa concelebrada por vários sacerdotes e presidida pelo frade franciscano José Isorna, amigo da família. Seguidamente o seu cadáver recebeu sepultura no cemitério compostelano de Boisaca; ali, no túmulo número 1439 , repousam os seus restos ${ }^{15}$.

\section{ALGUMAS REACÇÕES IMEDIATAS}

A obra de Carvalho, nomeadamente a sua produção escrita, não deixou de seguir presente e viva depois da sua morte. Nos anos sucessivos até se publicaram alguns trabalhos inéditos (como boa parte da sua poesia castelhana e o poemário galego O trebo das catro follas). E tardariam em aparecer os seus epistolários, ainda em grande parte inéditos ou em curso de publicação. Porém, não é aqui já lugar para expor esses capítulos que podemos considerar como um apêndice da sua biografia.

No entanto, podemos concluir resenhando brevemente alguns ecos da vida de Carvalho que aconteceram no mesmo ano do seu falecimento.

A Associação Cultural O Facho, da Corunha, organizou no mês de maio seguinte uma "Homenagem urgente a Ricardo Carvalho Calero (1910-1990)".

14 No artigo "In memoriam: Foi-se-nos D. Ricardo Carvalho Calero", Agália, 21 (1990), 107-114, e ainda noutras páginas do mesmo número, podem ver-se diversas informações relativas ao falecimento e enterro de Carvalho. Novas informações apareceram no número seguinte da mesma revista: "Na morte de D. Ricardo Carvalho Calero", Agália. 22 (1990), 217-221.

15 Nos actos fúnebres houve notórias ausências, só explicáveis por esse ambiente de hostilidade que existia contra ele em certos círculos da cultura galega. Neste contexto cumpre lembrarmos a presença de Ramón Pinheiro, que não deixou de assistir apesar de estar já gravemente doente naquela altura: faleceria nesse mesmo ano. 
A Associação Galega da Língua (AGAL) rendeu-lhe homenagem de lembrança da sua vida e de estudo da sua obra no III Congresso Internacional da Língua Galego-Portuguesa, que se celebrou no outono do mesmo 1990.

E a Câmara Municipal do Concelho de Ferrol instituiu a nome do escritor um certame anual de narrativa e de investigação linguístico-literária galega, que se convocou por primeira vez esse mesmo ano $1990^{16}$.

\section{REFERÊNCIAS BIBLIOGRÁFICAS}

Armesto, Victoria (1983). De cómo el Dr. Fernández Albor se vino para AP. La entrevista con Fraga. La Voz de Galicia, 29/VI/1983, 15.

Axeitos, Xosé L. (2020). Don Ricardo Carvalho Calero na Academia. Cadernos de Estudos Xerais, 17, 6-11.

Blanco, Carmen (1991). Carballo Calero: política e cultura. Sada: Ediciós do Castro.

Carballo Calero, Ricardo (1975). Historia da literatura galega contemporánea. 2. ed. Vigo: Galaxia.

Carballo Calero, Ricardo (1982). Teatro completo. Sada: Ediciós do Castro.

Carballo Calero, Ricardo (2006). Epistolario a Francisco Fernández del Riego. Vigo: Galaxia. Transcripción e edición de Dolores Vilavedra e Montserrat Pena ${ }^{17}$.

Carvalho-Calero Ramos, María V. (1992). Meu pai na lembrança. Agália, 29, 117.

Díaz Pardo, Isaac (2002). Algúns recordos de Carvalho Calero. En: Teresa López e Francisco Salinas, eds. Actas do Simposio Ricardo Carvalho Calero «Memoria do Século». A Corunha: Universidade da Coruña / Asociación Sócio-Pedagóxica Galega, 297-300.

Fernán Vello, Miguel A. e Pillado Mayor, Francisco (1986). Conversas en Compostela con Carballo Calero. Barcelona: Sotelo Blanco.

Filgueira Valverde, Xosé (1990). Carballo Calero. Faro de Vigo, 27/III/1990. [Recollido en: Sexto Adral. Sada: Ediciós do Castro, 1990, 306-307].

Henríquez Salido, M. Carmo (1992). Dom Ricardo Carvalho Calero na vida da Associaçom Galega da Língua. Agália, 29, 25-60.

Kremer, Dieter e Lorenzo, Ramón (eds.) (1982). Tradición, actualidade e futuro do galego. Santiago de Compostela: Xunta de Galicia - Consellería de Cultura.

16 Para ulterior informação sobre a vida e a obra de Carvalho Calero pode ver-se Montero (1993).

17 Excelente edição de um dos epistolários mais importantes de Carvalho Calero, tanto pela quantidade das cartas como pela sua própria natureza de relação com um dos seus amigos mais próximos e constantes. O livro está apresentado por um «Limiar» (pp. 7-15), esclarecedor e objetivo, da professora Dolores Vilavedra. Vem acompanhado de abundantes notas, de grande valor informativo. 
Marques, Maria A.; Santos, Ana P. Figueira; Rosmaninho, Nuno; Carvalho, António Breda; e Godinho, Rui (eds.) (1997). Correspondência de Rodrigues Lapa: Selecção (1929-1985). Coimbra: Livraria Minerva Editora.

Montero Santalha, J.-Martinho (1984). Ricardo Carvalho Calero, Da fala e da escrita (Ourense 1983) [recensão]. Grial, 84, 246-248.

Montero Santalha, J.-Martinho (1993). Carvalho Calero e a sua obra. Santiago de Compostela: Laiovento.

Rodríguez, José L. (2020). De A xente da Barreira (1951) para A gente da Barreira (1982): trinta anos à procura de um padrom. En: Francisco Cidrás, ed. Ricardo Carvalho Calero. As formas do compromiso. Santiago de Compostela: Universidade de Santiago de Compostela, 361-395.

Sotelo Blanco, Olegario. (2020). Conversas en Compostela con Carballo Calero, Romance Scórpio, Escritos sobre Castelao e Reticências, publicacións de Sotelo Blanco. O Farelo, 46, XIII.

Torres Feijóo, Elías (2020). José Luís Rodríguez nos trilhos da língua. Santiago de Compostela: Através Editora. 